\title{
ESTOMATERAPIA: UMA ESPECIALIDADE QUE EMERGE PARA A ENFERMAGEM BRASILEIRA
}

Vera Lucia Conceiçào de Gouveia Santos.* Afonso Henrique da Silva e Souza Junior

SANTOS, V.L.C. de G.; SOUZA JR., A.H. da S.e Estomate rapia: uma especialidade que emerge para a enfermagem brasileira. Rev. Esc. Enf. USP., v. 27., n.1., p. 9-14, abr. 1993.

Os autores relatam sua experiência com a organização e implementação do I Curso de Especializaçāo em Estomaterapia, realizado no Brasil, enfocando, inicialmente os aspectos conceituais e históricos acerca da especialidade, seguidos de informaçöes sobre o curso, a saber: objetivos, conteúdo programático, estratégias de ensino e processo avalintivo.

UNITERMOS: Estomaterapia. Especializaçāo em Enfermagem. Assistência a Ostomizados

O surgimento dos estomas, em literatura, remonta ao século XVIII, quando há a referência da primeira colostomia realizada na esposa de um pescador, em 1750, resultante de uma intervenção num caso de hérnia encarcerada. Podemos imaginar a qualidade de vida apresentada por essa mulher ao tornar-se colostomizada, em uma época "carregada" de preconceitos e quando não havia o menor conhecimento sobre cuidados específicos. Neste sentido, os escritos acerca dos cuidados e essa clientela existem apenas a partir de $1930^{1,6 .}$

A estomaterapia, como especialidade na área de saúde, constituiu uma iniciativa de Dr. Rupert Turnbull, da Cleveland Clinic, em Cleveland, Ohio, EUA, que estabeleceu a necessidade do "técnico em ostomia" em seu Serviço de Cirurgia Colo-retal (1958). Surge, então, a primeira especialista, Norma Gill, uma ileostomizada reabilitada e, portanto, com especial interesse na área. Em 1961, em dois Serviços, simultaneamente, no Ferguson-Drost-Ferguson Hospital em Michigan, EUA, e na própria Cleveland Clinic em Cleveland, surgem os programas de treinamento para pacientes que passam a atuar no cuidado dos próprios ostomizados ${ }^{1,6}$.

Em 1968, a criação da International Association of Enterostomal Therapy (IAET), permitiu o desenvolvimento de normas e padrões, não só para os Cursos de Especialização, agora para enfermeiros, como também para os

* Trabalho apresentado no $42^{\circ}$ Congresso Brasileiro de Enfermagem, em Natal, 1990.

* Enfermeira. Estomaterapeuta. Assistente do Departamento de Enfermagem Médico-Cirúrgica da Escola de Enfermagem da USP. COREN-SP - 11412.

*** Médico Professor Doutor do Departamento de Cirurgia do Aparelho Digestivo do Hospital das Clínicas da Faculdade de Medicina da USP. 
cuidados destinados a ostomizados e portadores de fístulas, estes últimos aprovados pela American Nurse's Association. De lá para cá, além da promoção de conferências, seminários, publicaçōes e estímulos para a abertura de novos cursos e formação de novos especialistas, a nível mundial, a cada dois anos ocorre o Congresso Mundial de Estomaterapeutas, denominado a partir do final da década de 70 como World Council of Enterostomal Therapy (WCET) $^{1}$. Atualmente, 1990, existem aprovados pela IAET, cerca de 42 "Escolas" de Estomaterapia no mundo, com 28 em pleno funcionamento, sendo gerados, nestes quase 30 anos, aproximadamente 4.500 especialistas ${ }^{10}$.

Nestc momento é necessário que nos reportemos a alguns aspectos conccituais que elucidem o que significa ser estomaterapeuta.

Segundo FOULKES ${ }^{2}$, JACKSON; BROADWELL ${ }^{4}$ e VUKOVICH; GRUBB $^{9}$, o estomaterapeuta (ET) é o enfermeiro especialista com conhecimento, treinamento e habilidade para o cuidado de qualquer tipo de ostomizado e de portadores de fístulas, feridas e incontinências fccal c urinária. SREDL; WILHITE ${ }^{8}$ acreditam que este especialista deve ser "preparado para ajudar o indivíduo candidato a ser ostomizado, ou aquele que já o é, a avaliar o seu próprio potencial, a fim de resolver os problemas nāo só de ordem física como também os de ordem psicológica, social, espiritual, econômica c outros relacionados ao processo reabilitatório". Para FOULKES ${ }^{2}$ e LÁZARO VALVERDE ${ }^{5}$, o ET deve assumir todas as funções dirigidas no sentido de garantir e melhorar o nível de saúde individual e coletivo do grupo de ostomizados, ou de portadores de fístulas e outras drenagens que requerem um trabalho especializado.

Assim, a estomaterapia pode ser considerada como arte e ciência e o especialista deve combinar sensibilidade para com a clientela afetada por problemas bio-psico-sociais de alta complexidade, com habilidade técnica que permita facilitar o sucesso da reabilitação ${ }^{4}$.

Segundo, JACKSON; BROADWELL ${ }^{3.4}$, na evolução da enfermagem como profissāo, as justificativas para o desenvolvimento das especialidades, dentre as quais a Estomaterapia, são fundamentais como: qualidade do cuidado, custo-efetividade, satisfação e educação da clientela. Daí o sucesso de qualquer cspecialidade profissional na enfermagem demandar o envolvimento com o cuidado, ensino, pesquisa, consultoria e atividades administrativas, que discriminam e definem desta forma, a amplitude da atuaçāo do próprio estomaterapeuta $2,4,5,6,7,8,9$

Essas explanações introdutórias permitem-nos vislumbrar a Estomaterapia como uma nova especialidade na área de saúde, particularmente para a enfermagem, quer a nível internacional, já referendada, quer a nível nacional, o que ampliaria o "espaço" profissional do enfermeiro, exatamente no momento crítico, em que se encontra, dessa busca e conquista. Estes fatores associados ao aumento crescente da população de ostomizados, e ao avanço 
tecnológico na área do cuidado de pele, feridas e fístulas, corroboram a necessidade de tal profissional especializado.

A experiência pessoal com ostomizados, como enfermeira, tem-se desenvolvido nos últimos 7 anos, envolvendo desde a participação na organização de um Núcleo de Assistência no Hospital das Clínicas da Faculdade de Medicina da Universidade de São Paulo (N.A.O.HCFMUSP), a prestação de assistência ambulatorial no mesmo Serviço e a inserção do tema no conteúdo programático da disciplina Enfermagem Médico-Cirúrgica, do Curso de Graduaçāo em Enfermagem da Escola de Enfermagem da USP, com abordagem teórico-prática, até o desenvolvimento de alguns trabalhos científicos nessa área, inclusive o tema da dissertação de Mestrado, já concluída e apresentada sobre a auto-irrigação intestinal em colostomizados.

Nesse período, como enfermeira, tive a oportunidade de realizar um Curso de Especialização em Estomaterapia na Escuela de Enfermeria, Fisioterapia y Podologia de la Universidad Complutense de Madrid, através do qual obtive o título de estomaterapeuta. Assim, a vivência anterior, associada a um título recém-conquistado, à vinculaçāo, como docente, a uma instituição de ensino superior reconhecida internacionalmente e à constatação da inefetividade da assistência prestada ao ostomizado, motivaram a organização e implementação do I Curso de Especializaçāo em Estomaterapia, pioneiro no Brasil, ocorrido em abril e maio de 1990 , e cujo relato constitui o objetivo primordial deste trabalho.

Este primeiro curso foi coordenado pelos autores deste relato, estomaterapeuta e médico coloproctologistá, que têm atuado conjuntamente desde a org anizaçāo do N.A.O., conforme mencionado anteriormente, até o dia-a-dia das atividades desse serviço voltadas para a assistência, ensino e pesquisa na área da estomaterapia.

O curso, destinado a enfermeiras com pelo menos dois anos de atuação profissional e com experiência mínima de 6 meses nas áreas de atendimento hospitalar ou ambulatorial em Coloproctologia, Urologia ou Pediatria, foi organizado em 3 fases: divulgaçāo do curso, seleção dos candidatos e implementaçăo do conteúdo programático.

A fase de divulgação foi executada pelo Serviço de Cultura e Extensão Universitária da própria Escola de Enfermagem, por meio de programas e cartazes distribuídos para os principais hospitais e cscolas de enfermagem do país.

O processo seletivo foi executado pelos coordenadores por meio de análise do currículo do candidato, seguida de entrevista, ambas efetuadas somente com aqueles enfermeiros que preenchiam os requisitos exigidos no momento da inscrição, e que totalizaram 20 elementos. A análise curricular objetivava o levantamento de dados acerca, principalmente, da experiência profissional com ostomizados e à sua atualização no assunto, obtida em 
Cursos, Congressos e similares e de publicações científicas; a entrevista versava basicamente sobre a fonte de informaçōes acerca do curso, a motivação pessoal para fazê-lo, as expectativas quanto ao mesmo e às perspectivas futuras após sua aprovação no curso. Dez candidatos foram selecionados, sendo sete da cidade de São Paulo c três de outros estados (Paraná, Santa Catarina c Rio Grande do Norte).

A tcrceira fase foi a realização do curso.

Os objetivos do curso consistiram em capacitar o enfermeiro para: 1 . assistir tanto o indivíduo ostomizado, nas fases intra e extra-hospitalar, como o portador de fístulas digestivas; 2 . iniciar a investigação científica na área da estomaterapia; 3 . reconhecer os fatores determinantes no processo saúdedoença que levam às operaçōes para a construção de estomas intestinais c urinários; 4. rcconhecer os aspectos organizacionais necessários para a formação de Serviços de Assistência c 5. desenvolver o ensino, nessa área, junto a clicntes, familiares c cquipes de enfermagem c multiprofissional.

O contcúdo programático, previsto para uma carga horária de 365 horas distribuídas $\mathrm{cm}$ teóricas $\mathrm{c}$ práticas, abrangeu: revisão de anatomia $\mathrm{e}$ fisiologia dos tratos digestivo e urinário $\mathrm{c}$ da pele; abordagem das doenças que levam à formação de estomas intestinais c urinários, inclusive aspectos epidemiológi$\cos$, clínicos c terapêuticos; aspectos técnicos de formação dos cstomas; complicaçōes dos estomas; cstomas em pediatria; fístulas digestivas: patogênese, fisiopatologia e terapêutica; suporte nutricional; aspectos gerais c específicos dos tratamentos radioterápico e quimioterápico do paciente oncológico; aspectos psicológicos, sexuais, sociais c nutriciona is dos ostomizados; assistência sistematizada em estomaterapia intra e extra-hospitalar; bases para a organização de serviços de assistência a ostomizados; as Associaçõcs de Ostomizados; materiais c cquipamentos $\mathrm{cm}$ cstomaterapia (avaliação e apresentação) e bases de metodologia de pesquisa quantitativa c qualitativa. Para tanto contamos com a colaboração de diversos profissionais pertencentes ou não à Universidade.

Quanto às cstratégias de ensino, foram utilizadas aulas expositivas; seminários; estudos de caso e atividades em campo de prática, tanto em Unidades de Internação como cm Ambulatório.

O sistema de avaliação consistiu em reuniōes no decorrer do curso, além dos processos formais habituais como: apresentação de estudos de caso, seminários, uma prova teórica, participação nas discussões, desempenho no campo de prática, auto-avaliação e elaboração e exposiçāo de um plano de pesquisa, como trabalho final.

Esta experiência preliminar mostrou-se bastante efetiva segundo nossa avaliação c das novas estomaterapeutas, algumas das quais já se encontravam cm franca atuação nos próprios Serviços, com a organização de Núcleos de 
Assistência, elaboração de programas de educação continuada e desenvolvimento dos planos de pesquisa.

Evidentemente, a partir de agora surgem novas perspectivas resultantes do aumento desse grupo de especialistas e, o que é mais importante, em pólos regiona is fora do Estado de São Paulo. Estas perspectivas envolvem continuidade da realização de cursos de especialização; elaboração de trabalhos científicos relacionados principalmente aos cuidados e aos dispositivos específicos para essa clientela; discussão acerca da especialidade quanto ao seu reconhecimento pelos órgãos competentes e discussão sobre a criação de uma sociedade brasileira de estomaterapia filiada a organismos internacionais, todos objetivando, essencialmente, a melhoria da qualidade assistencial e conseqüentemente, do processo de reabilitação do ostomizado na realidade brasileira.

SANTOS, V.L.C. de G; SOUSA JR, A. H. da S. e. Enterostomal therapy: a new specialty emerging for the Brazilian nursing. Rev.Esc. Enf. USP, v. 27, n. 1, p. 9-14, apr., 1993.

The authors relate the experience in the organization and development of the I Enterostomal Therapy Specialization Course, the pioneer in Brazil. They report the concepts and history about enterostomal therapy as a specialty; discuss the objectives, contents, teaching strategies, and evaluation process of the course.

UNITERMS: Ostomy nursing care. Enterostomal The rapy.

\section{REFERÊNCIAS BIBLIOGRÁFICAS}

1. ANDERSON, F.J. History enterostomal therapy. In: BROADWELL, D.C.; JACKSON, B.S. Principles of ostomy care. Saint Louis, Mosby, 1982. cap. 3, p. 14-6.

2. FOULKES, B. E papel de la enfermera en el cuidado de estoma. In: BRECKMAN, B. Enfermeria del estoma. Madrid, Interamericana, 1987. cap. 17, p. 213-8.

3. JACKSON, B.S.; BROADWELL, D.C. Brinciples of ostomy care. Saint Louis, Mosby, 1982. cap. 1, p. 3-7: Philosophy and issues in ostomy care.

4.

. Principles of ostomy care. Saint Louis, Mosby, 1982. cap.

2, p. 8-13: Role of the enterostomal therapy practitioner.

5. LÁZARO VALVERDE, J.L. Metodd ogia en la consul ta de la enfermera estomaterapeuta. Madrid, Escuela Universi tária de Enfermeria, Fisioterapia y Podologia de la Universidad Complutense de Madrid, 1988. /Mimeografado/.

6. LENNEBERG, E. Role of enterostomal therapist and stoma rehabilitation clinics. Cancer, v. 28 , n. 1, p. 266-9, 1971.

7. MAHONEY, J.M. Guide to ostomy nursing care. Boston, Litte Brown, 1976. cap. 9, p. 177-89: Rehabilitation.

8. SREDL, D.; WILHITE, M. The enterostomal therapist: a new breed of nurse. Superv, Nurse, $v$. 11, n. 1, p. 51-2, 1980.

9. VUKOVICH, V.; GRUBB, R.D. Care of the ostomy patient. 2 ed. Saint Louis, Mosby, 1977. cap. 2, p. 5-37: Functions of the ostomy nurse. 
10. WORLD COUNCIL OF ENTEROSTOMAL THERAPISTS. An association of nurses. Education guidelines: Section Ull. Nedlands. Presswise Publication. 1990. 